\title{
Erratum to: Thermal Fatigue Evaluation of Pb-Free Solder Joints: Results, Lessons Learned, and Future Trends
}

\author{
RICHARD J. COYLE $®{ }^{1,4}$ KEITH SWEATMAN ${ }^{2}$ and BABAK ARFAEI ${ }^{3}$ \\ 1.-Alcatel-Lucent Bell Labs, Murray Hill, NJ, USA. 2.-Nihon-Superior, Osaka, Japan. 3.-Universal \\ Instruments Corporation, Conklin, NY, USA. 4.-e-mail: richard.coyle@alcatel-lucent.com
}

Erratum to: JOM, Vol. 67, No. 10, 2015

DOI: 10.1007/s11837-015-1595-1

Due to an editing mistake, the content of Table II was erroneously replaced. Table II should read:
Table II. Temperature cycling profiles used in the experimental program

\begin{tabular}{|c|c|c|c|}
\hline $\begin{array}{l}\text { Minimum } \\
\text { temp. }\left({ }^{\circ} \mathbf{C}\right)\end{array}$ & $\begin{array}{l}\text { Maximum } \\
\text { temp. }\left({ }^{\circ} \mathrm{C}\right)\end{array}$ & Temp. range $\left({ }^{\circ} \mathrm{C}\right)$ & $\begin{array}{c}\text { Dwell } \\
\text { time (min) }\end{array}$ \\
\hline 0 & 100 & 100 & 10 \\
\hline 0 & 100 & 100 & 60 \\
\hline-40 & 100 & 140 & 10 \\
\hline-40 & 100 & 140 & 60 \\
\hline 25 & 125 & 100 & 10 \\
\hline 25 & 125 & 100 & 60 \\
\hline-15 & 125 & 140 & 10 \\
\hline-15 & 125 & 140 & 60 \\
\hline-40 & 125 & 165 & 10 \\
\hline
\end{tabular}

